\title{
Hepatic hypertrophic osteoarthropathy and liver transplantation
}

\author{
Pauline Pitt, Alex Mowat, Roger Williams, Eric Hamilton
}

\begin{abstract}
Objectives-To document the variety of liver diseases and the clinical picture of hepatic hypertrophic osteoarthropathy (HOA) complicated by arthritis and to report the effects of successful liver transplantation on this disabling condition.

Methods-Seven patients with severe liver disease (two biliary atresia, two primary sclerosing cholangitis, one Wilson's disease, one primary biliary cirrhosis (PBC) and one alcoholic cirrhosis) complicated by radiologically proven hepatic HOA and suffering from arthritis are described.

Results-In four of the six patients who required hepatic transplantation for inadequate liver function successful grafting was achieved with complete clinical remission of the painful arthritis. This occurred three days to 18 months later. Conclusions-Hepatic HOA with arthritis occurs in a variety of liver diseases. Despite resistance of this arthritis to conventional therapies, successful liver transplantation was associated with complete clinical remission in four of the cases reported.
\end{abstract}

(Ann Rheum Dis 1994; 53: 338-340)

Hepatic hypertrophic osteoarthropathy (HOA) was originally described in $1895^{1}$ and is characterised by periosteal reactions affecting the shafts of long bones. It is well documented from case reports ${ }^{2-6}$ in studies involving larger groups of patients. ${ }^{78}$ Hepatic HOA with arthritis, however, is rare and only three cases are recorded in the largest series.

This paper describes seven patients from a liver transplant centre suffering from hepatic HOA with arthritis.

\section{Case reports}

The clinical details of the patients are given in the table.

All patients received post-transplantation immunosuppression with azathioprine $1 \mathrm{mgm} /$ $\mathrm{kgm}$, cyclosporin $5 \mathrm{mgm} / \mathrm{kgm}$ and high dose prednisolone.

CASES 1 AND 2

Two female children required Kasai procedures in infancy for biliary atresia. This operation involves excision of the extrahepatic biliary tree and construction of a roux-en-y loop to the remaining biliary tree in an attempt to reduce intrahepatic cholestasis. Unfortunately, both eventually required liver transplantation.

Nine months before transplantation, patient 1 presented with painful knees with effusion and slight swelling of both elbows. Radiographs of the elbows showed obvious periostitis and three months later she was wheelchair dependant because of severe knee pain. Three days after liver transplantation for inadequate liver function (serum bilirubin $121 \mathrm{umol} / \mathrm{l}$, normal range 3-20 umol/1, albumin $39 \mathrm{G} / \mathrm{L}$, normal range 35-50 G/L and INR 1) she had no joint pain and two years post transplant she remains pain free and there is no evidence of joint effusion.

Patient 2 had bilateral painful knee effusions and associated fixed flexion deformities. Her initial transplant failed and four months after a second successful transplant she was pain free. Eighteen months post transplant there was no knee effusion or joint pain.

CASE 3

A nineteen year old girl presented in acute liver failure (bilirubin $618 \mathrm{umol} / \mathrm{l}$ albumin $34 \mathrm{G} / \mathrm{L}$ and INR 2.8) with fulminant Wilson's disease. No note of her joints was made at this critical time and she underwent liver transplantation four weeks later. Immediately post transplant she was wheelchair dependant with painful knees and eight months later she still had knee pain with effusions. There was evidence of bilateral periosteal reaction on radiographs but no chondrocalcinosis which may occur with Wilson's disease. Eighteen months post transplant she had no joint symptoms.

CASE 4

A twenty one year old man with a seven year history of primary sclerosing cholangitis and ulcerative colitis presented with deterioration in liver function and the development of painful knees, ankles and wrists. On examination he was clubbed and had knee effusions with local tenderness in his wrists and ankles. Endoscopic investigation at this time did not demonstrate oesophageal varices. Radiographs showed obvious periostitis. Liver transplantation was carried out three months later (bilirubin $196 \mathrm{umol} / \mathrm{l}$, albumin $19 \mathrm{G} / \mathrm{L}$ and INR $1 \cdot 8$ ). Unfortunately he died postoperatively. 
Details of patients with hepatic hypertrophic osteoarthropathy and arthritis

\begin{tabular}{|c|c|c|c|c|c|c|}
\hline $\begin{array}{l}\text { Patient } \\
\text { Number }\end{array}$ & Age & Diagnosis & Clubbing & foints & $\begin{array}{l}\text { Outcome } \\
\text { Transplant }\end{array}$ & Result \\
\hline 1 & 11 & Biliary atresia & + & Knees & Successful & + \\
\hline 2 & 11 & Biliary atresia & + & Knees/elbows & Successful & + \\
\hline 3 & 19 & Wilson's disease & + & Knees & $\begin{array}{l}\text { Successful for } \\
18 / 12\end{array}$ & + \\
\hline 4 & 21 & $\begin{array}{l}\text { Sclerosing cholangitis, } \\
\text { ulcerative colitis }\end{array}$ & + & $\begin{array}{l}\text { Knees/elbows/ } \\
\text { wrists }\end{array}$ & Died & N/A \\
\hline 5 . & 45 & $\begin{array}{l}\text { Sclerosing cholangitis, } \\
\text { hepatocellular } \\
\text { carcinoma }\end{array}$ & + & $\begin{array}{l}\text { Knees/ankles/ } \\
\text { wrists }\end{array}$ & $\begin{array}{l}\text { Successful only } \\
\text { for } 2 / 12\end{array}$ & + \\
\hline 6 & 30 & PBC & + & $\begin{array}{l}\text { Knees/ankles/ } \\
\text { wrists }\end{array}$ & $\begin{array}{l}\text { Chronic non A } \\
\text { non B }\end{array}$ & - \\
\hline 7 & 44 & Alcoholic cirrhosis & + & $\begin{array}{l}\text { Knees/ankles/ } \\
\text { wrists }\end{array}$ & N/A & N/A \\
\hline
\end{tabular}

Note: Result column + indicates resolution of arthritis after transplantation, - indicates no improvement of arthritis after transplant.

CASE 5

A forty five year old man with a 12 year history of sclerosing cholangitis complained of painful knees, elbows and wrists. His liver function had recently deteriorated and he presented with bleeding oesophageal varices.

Two years previously liver biopsy had been reported as showing hepatocellular carcinoma. On examination he was clubbed and had large knee effusions with tender elbows and wrists. Radiographs showed periostitis of the medial borders of both femora, left lower humerus and left radius at the wrist. Because of continuing deterioration in liver function (bilirubin $176 \mathrm{umol} / \mathrm{l}$, albumin $28 \mathrm{G} / \mathrm{L}$ ) he underwent transplantation. Two months later he was asymptomatic from HOA and on examination had only a trace of fluid in his knees. He has subsequently died.

CASE 6

A thirty year old woman with PBC, seen for pretransplant assessment, (bilirubin $340 \mathrm{umol} /$, albumin $30 \mathrm{G} / \mathrm{L}$ and INR $1 \cdot 3$ ) was found to be clubbed with a swollen but non-painful left knee. There was no evidence of oesophageal varices on endoscopy. A month later liver transplantation was performed which failed and she required a second transplant. Three months after this she had bilateral painful knee effusions and radiographs revealed periosteal reaction in the knees, wrists and ankles. The graft had functioned inadequately probably due to chronic non A non B viral hepatitis. The arthritis has persisted throughout this five year post-transplant period despite ongoing immunosuppressive therapy, currently provided by prednisolone $10 \mathrm{mgm}$ daily and cyclosporin $250 \mathrm{mgm}$ twice a day.

CASE 7

Case 7 has not yet required transplantation. $\mathrm{He}$ is included as he demonstrates the typical clinical and radiological picture (fig) described in this report and suffers from another variety of liver disease. $\mathrm{He}$ is a forty four year old man with alcoholic liver disease complicated by portal hypertension and bleeding oesophageal varices. A few months following a haematemesis he complained of painful ankles, knees and wrists. When reviewed four years later he

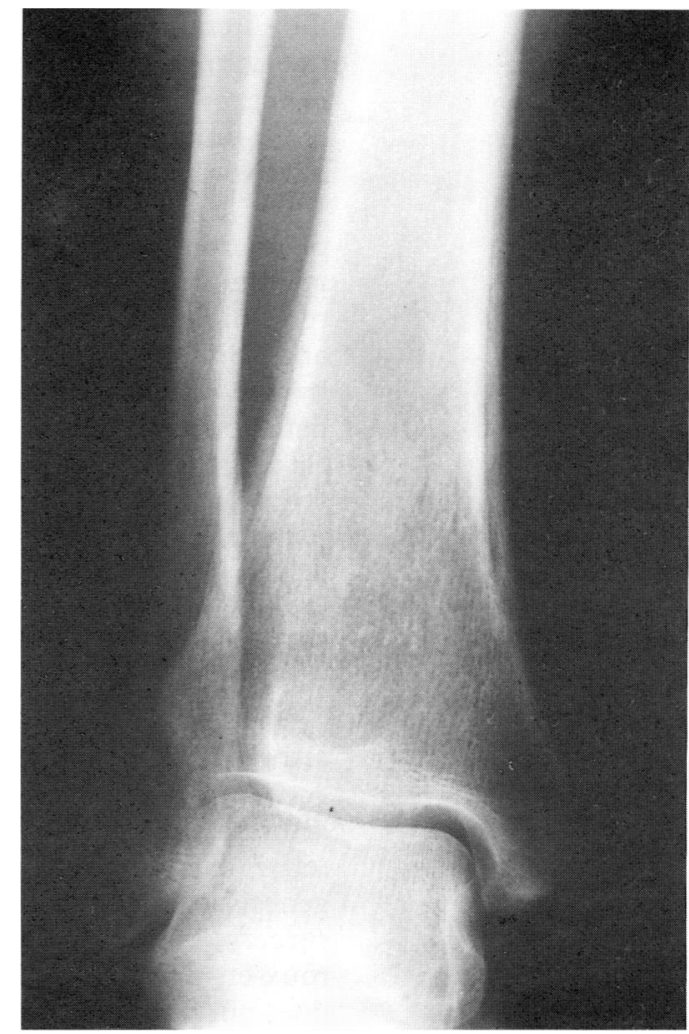

Radiograph of the ankle showing periosteal reaction on both sides of the tibia in patient 7 .

was clubbed and there was a right knee effusion as well as tenderness to palpation of the bones just above the ankles and wrists.

\section{Discussion}

These reported patients with hepatic HOA and arthritis suffered from a variety of liver diseases. They are representative of patients referred to the liver unit for transplantation where $25 \%$ suffer PBC, $7 \%$ biliary atresia, $5 \%$ primary sclerosing cholangitis, $4 \%$ alcoholic cirrhosis and $59 \%$ other causes including acute Wilson's disease. This contrasts with Epstein's original report ${ }^{7}$ where $\mathrm{PBC}$ was the diagnosis in $50 \%$ of cases of hepatic HOA.

All patients were clubbed compared with $30 \%$ of patients undergoing hepatic transplantation in the unit and the arthritis was universally characterised by knee effusion. There was also involvement of other joints including ankles, wrists and elbows. In all cases, the arthritis was associated with considerable morbidity which resulted in pain and limitation of movement. Conservative management including injection with corticosteroid and the use of non-steroidal anti-inflammatory drugs was of no benefit to any patient.

The age of the patients at presentation of the arthritis ranged from 11 to 44 years and in five of the seven cases joint symptoms were most severe immediately pre liver transplantation, occurring at a time of marked liver decompensation. In patient 3 it is very probable that arthritis preceded transplantation as she was wheelchair dependant immediately following surgery. The presentation of arthritis at a time of severe liver decompensation is highlighted in 
the literature by a report of arthritis first presenting at the time of liver transplant rejection ${ }^{9}$ and it is interesting that case 5 , where graft function was inadequate, continues to have severely painful swollen knees.

Of the six patients undergoing transplantation, a successful graft was achieved in four, and in these there was complete resolution of symptoms between three days and 18 months. This observation is supported by the report of another centre ${ }^{10}$ where two patients with hepatic HOA, one with crippling arthritis, had complete resolution of their symptoms following transplantation.

In the patients reported here arthritis occurred in six of the seven cases at a time of severe liver decompensation and in four patients, in whom liver transplantation was successful, the symptoms resolved.

In case 5, despite immunosuppression, arthritis has persisted, and it is unlikely that such treatment explains the resolution of the arthritis. In cases 1 and 2 pretransplant bacterial overgrowth, implicated in the pathogenesis of arthritis in gastrointestinal bypass surgery, is not responsible for arthritis as the roux-en-y loop is not distended so the patient does not have the features of 'blind loop'.

To date there is no UK report documenting resolution of $\mathrm{HOA}$ in patients undergoing cardiac or heart and lung transplantation.

It appears therefore that the damaged liver produces or fails to metabolise substances responsible for the local changes in bone metabolism in these patients with arthritis and HOA.

\section{Conclusion}

This paper reports the clinical picture of arthritis in patients with a variety of liver diseases complicated by HOA. The observation that successful liver transplantation is associated with a resolution of pain and joint effusion is interesting and warrants further investigation.

1 Gilbert A, Fournier L. La cirrhose hypertrophique avec ictere chez l'enfants. Revue des Maladies de L'enfanee 1895; 13: 309 .

2 Obermeyer F. Knochenveranderungen bei chronischem icterus. Wien Klin Rdsch 1897; 11: 625-45.

3 Beutenmuller $\mathrm{H}$. Toxigene osteoperiostitis ossificans bei chronischem icterus. Berlin Klin Wochenschr 1908; 45. 1000-4.

4 Buchan D J, Mitchell D M. Hypertrophic osteoarthropathy in portal cirrhosis. Ann Intern Med 1967; 66: 130-135.

5 Kieff E D, McCarthy D J. Hypertrophic osteoarthropathy in a patient with alcoholic cirrhosis. Arthritis Rheum 1969; 12: $261-71$

6 Morgan A G, Walker W C, Mason M K, et al. A new syndrome associated with hepatocellular carcinoma. Gastroenterology 1972; 63: 340-50.

7 Epstein O, Ajdukiewicz A B, Dick R, Sherlock S. Hypertrophic hepatic osteoarthropathy. Clinical, roentgenologic, biochemical, hormonal and cardiorespiratory studies, and review of the literature. Am $\mathcal{f}$ Med 1979; 67: 88-97.

8 Mills $\mathrm{P}$ R, Vallance $\mathrm{R}$, Birnie G, et al. A prospective survey of radiological bone and joint changes in primary biliary cirrhosis. Clin Radiol 1981; 32: 297-302

9 Wolfe S M, Aelion J A, Gupta R C. Hypertrophic osteoarthropathy associated with a rejected liver transplant. F Rheumatol 1987; 14: 147-151.

10 Vickers C, Herbert A, Neuberger J, Elias E. Improvement in hypertrophic osteoarthropathy after liver transplantation. Lancet 1988; 2: 968 